\title{
Portfolio Allocation and Asset Returns in an OLG Economy with Increasing Risk Aversion ${ }^{1}$
}

\author{
Amadeu DaSilva \\ California State University, Fullerton \\ Mira Farka ${ }^{2}$ \\ California State University, Fullerton
}

January 2013

\begin{abstract}
We examine asset returns, equity premium and portfolio allocation in a threeperiod OLG model with increasing risk aversion $(I R A)$. The introduction of IRA leads to: a) an increase in all security returns, b) a higher risk premium, c) a reduced level of saving, and d) a decline in risky portfolio shares. Results are driven by small differences in the risk aversion parameters. The relative difference between the two risk aversions (how much more risk-averse old agents are relative to the middle aged) matters more than the average risk aversion in the economy (how much more risk averse both cohorts are).
\end{abstract}

JEL Classification: G0, G12, D10, E21.

Key Words: Equity premium puzzle, Overlapping generations model, Increasing Risk Aversion, Portfolio allocation.

\footnotetext{
${ }^{1}$ We thank John Donaldson for numerous comments and suggestions. We also thank Stijn Van Nieuwerburgh, Christos Giannikos, John Geanakoplos, Rajnish Mehra, Bruce Preston, Dan O'Flaherty, Richard Clarida and conference participants of the 2010 Financial Management Association. This research was sponsored by the Faculty Research Grant of California State University Fullerton and the Graduate Research Program, Columbia University.

${ }^{2}$ Corresponding author: California State University, Fullerton, Department of Economics, 800 N. State College Blvd., Fullerton, CA 92834. e-mail: efarka@fullerton.edu, Tel: (657) 278-7281, fax: (657) 278-3097.
} 


\section{Introduction}

The issue of optimal portfolio allocation has received considerable attention in recent years. This is motivated partly by the steady shift in population demographics as well as by an increase in market participation rates in advanced economies during the past three decades. Of particular concern is the ageing of the baby boom generation and its impact on asset returns, portfolio allocations, and the level of private and national savings. ${ }^{1}$ According to the U.S. Bureau of the Census, the U.S. population over the age of 65 , currently at $13 \%$, is expected to grow to over $20 \%$ by 2030 ; the proportion of US households headed by someone 65 years or older is expected to increase to roughly $40 \%$ by 2040 , compared to $22 \%$ in 1996 . In addition, this age cohort is wealthier than the average population: in 2005 the median financial wealth of households aged 65 or older was $\$ 40,000$ compared to an average median wealth of $\$ 15,420$ for the other age cohorts.

At the same time, a large body of empirical work has found evidence that risk aversion tends to increase with age. Morin and Suarez (1983) study the effect of age on the specific composition of risky assets in an investor's portfolio and conclude that risk aversion increases with age. Bakshi and Chen (1994) use asset allocation data post1945 for the U.S. and document a strong pattern of an increase in risk aversion with age. Riley and Chow (1992) derive risk aversion indices from actual asset allocation and found that risk aversion decreases with age until 65 and then increases significantly. More recent studies also document a positive relationship between age and risk aversion (Palsson (1996), Lee and Hanna (1995), and Sung and Hanna (1996)). ${ }^{2}$

\footnotetext{
${ }^{1}$ See for example, Yoo (1994), Brooks (2000), Davis and Li (2003), Ameriks and Zeldes (2004), Geanakoplos, Magill and Quinzii (2004), Goyal (2004), and Poterba (2001, 2004).

${ }^{2}$ It should be noted that evidence on the relationship between risk aversion and age is not entirely conclusive (see for example, Bellante and Saba (1986), and Jianakoplos and Bernasek (1998), and Wang and Hanna (1997)). The lack of consensus in the empirical literature appears to be driven partly by the fact that results are highly sensitive to wealth measurements, and partly because age and wealth are highly correlated. Nonetheless, there seems to be a general agreement that risk aversion increases beyond age 65 (retirement age). This is corroborated by a drop in stock market participation rates and a decline in risky portfolio shares for agents older than 65.
} 
As the share of older, wealthier, and more risk averse agents continues to grow, it is important to understand the impact of these demographic shifts on asset prices, savings and portfolio allocation. However, there seems to be little consensus in the existing literature on these issues, with predictions ranging from one extreme view of a potential "market meltdown" associated with the retirement of baby boomers, to another extreme of a very modest - if any - effect of the changing demographics on asset returns and the composition of household balance sheets. ${ }^{3}$

This paper presents an asset pricing model that investigates the equity premium puzzle and explores agents' savings/investment and portfolio allocation decisions. The novelty comes from introducing increasing risk aversion $(I R A)$ into the three-period overlapping generations (OLG) model framework of Constantinides, Donaldson, and Mehra (CDM) (2002) with borrowing constraints. This setup allows us to investigate the impact of IRA on security returns, level of savings, and portfolio allocation. We then compare our findings with IRA against the baseline economy of CDM with nonincreasing risk aversion.

Following CDM (2002), we assume that there are three age cohorts (young, middleaged and old), each facing different sources of uncertainty on wage and equity income; the attractiveness of equity depends on the stage of the life-cycle. The young, for whom equity is a "hedge" against future wage shocks, are constrained from participating in securities markets. In the absence of participation from the young, asset prices are exclusively driven by middle-aged investors for whom equity is less desirable since they do not face wage uncertainty. As in CDM (2002), the borrowing constraint feature of the model increases equity returns (because the middle-aged require a higher premium to hold equity), reduces the risk-free rate (because the young are unable to borrow), and thus increases the equity premium.

The key insight of this paper is the introduction of increasing risk aversion: consis-

\footnotetext{
${ }^{3}$ See, for example, Yoo (1994), Poterba (2001), Brooks (2000), Abel (2003), and Geanakoplos, Magill and Quinzii (2004).
} 
tent with the empirical evidence, we assume that older agents are more risk averse than middle-aged ones. There are several implications from this setup. First, it allows us to separate the effect on security returns, savings, and asset allocation of the two risk aversion parameters. Interestingly, we find that the relative difference between the two risk aversions (how much more risk averse old agents are relative to the middle aged) matters more than the average level of risk aversion in the economy (how much more risk averse both cohorts are). It is important to stress that results are driven by fairly small differences in the risk aversion parameters: even a small increase in older agents' risk aversion produces significant results. Second, the introduction of IRA improves the performance of the CDM baseline model: our results match the equity premium and explain observed patterns in risky portfolio shares for reasonable levels of risk aversion. The presence of $I R A$ reinforces the impact of the borrowing constraint of CDM on equity prices, thus delivering a higher equity premium for all levels of risk aversion. Third, unlike the majority of other works, we study both equity premium and portfolio allocation decisions in a unified framework.

Overall, the effects of $I R A$ on a life cycle model are significant. Our results suggest that an increase in risk aversion associated with population ageing has the following implications for financial markets: 1) an increase in all security returns with equity returns dominating bond returns, 2) a higher equity premium, 3) a reduced level of saving, and 4) a decline in the portfolio share of the risky asset. These results are consistent with the empirical evidence: the equity premium generated by $I R A$ is in line with the historical average and the portfolio share of the risky assets is in the 40-50\% range.

Our work is related to two strands of literature. The first one focuses on reconciling the high equity premium observed in the data with theoretical findings of reasonably specified asset pricing models. Studies in this area have proposed several generalizations of the key features of the Mehra and Prescott (1985) model ranging from preference 
modifications, lower tail risks, survival bias, incomplete markets, market imperfections, limited participation, macroeconomic shocks, and behavioral explanations. ${ }^{4}$ This paper falls firmly within this literature and contributes to it by analyzing the equity premium in a simple and arguably more realistic setting.

The second strand of literature deals with household portfolio choices, and comprises both theoretical and empirical studies on the life cycle patterns of asset allocation and participation rates. Early models with complete markets predict that the optimal fraction of wealth invested in risky asset is constant, independent of wealth and age, and dependent only on the risk aversion and the moments of asset returns (Samuelson (1969) and Merton (1971)). When calibrated to historical values of asset returns, these models predict that the appropriate portion of wealth placed in risky asset is large sometimes higher than $100 \%$.

However, a large body of empirical work has documented a number of empirical regularities that contradict the predictions of the theory. First, the share of the risky asset in the portfolio is considerably below 100\%: Bertraut and Starr-McCluer (2002) estimate it to be around $54.4 \%$. Second, there is a strong relationship between age and the share invested in the risky asset. For example, Fagereng (2009) finds that households hold a remarkably stable share of risky assets (around 39\%) up until the age of 50 , which is then reduced to around $30 \%$ by the time of retirement. Andersson (2001) shows that the fraction of risky asset follows a hump-shaped age profile, while the share of the "safe" asset has a distinct U-shaped pattern. ${ }^{5}$

\footnotetext{
${ }^{4}$ See, for example, Rietz (1988), Weil (1989), Constantinides (1990), Epstein and Zin (1990), Telmer (1993), He and Modest (1995), Heaton and Lucas (1997), Basak and Cuoco (1998), Campbell and Cochrane (1999), Bansal and Yaron (2004), McGrattan and Prescott (2003), Constantinides, Donaldson and Mehra (2002), Barro (2006), DaSilva and Giannikos (2006), Hong and Stein (2007), and DaSilva, Farka and Giannikos (2011).

${ }^{5}$ The empirical relationship between age and portfolio shares of the risky asset is not entirely clearcut partly because of the identification issues related to age, time, and cohort (birth year) effects. For example, a few studies find that conditional on owning risky any assets, the share of financial wealth held in risky assets is relatively stable with age except for the very young and the very old households (Ameriks and Zeldes (2004), Poterba (2001), Bertraut and Starr-McCluer (2002), and McCarthy (2004)).
} 
The discrepancies between early theoretical predictions and recent empirical findings have led to the development of a large body of theoretical work which has attempted to reconcile observations with theory. Standard models are extended to analyze asset allocation decision in both infinite and finite horizon models and include a few key features such as uninsurable labor income risk, preference heterogeneity, market participation costs, precautionary and retirement savings, bequest motives, small probability of disastrous events, and housing investment. ${ }^{6}$ Our model further extends these efforts by introducing $I R A$ in a life cycle model which delivers equity premium and risky allocation shares that are consistent with the recent empirical evidence without assuming unreasonable parameter values.

The rest of this paper is organized as follows. Section 2 introduces the model. Section 3 discusses the model calibration. Section 4 presents and discusses our findings. Results from our IRA model are compared to the non-increasing risk aversion baseline model. Section 5 concludes.

\section{The Model}

We consider the three-period OLG exchange economy of Constantinides, Donaldson, and Mehra (2002), where each generation lives as young, middle-aged, and old. Each consumer-generation is modeled as a representative agent in order to focus on acrossgeneration instead of within-generation heterogeneity. There is only one consumption good which perishes at the end of each period. All prices, wages, consumption, dividends, and coupons payments are quoted in terms of this single consumption good. Following CDM (2002), we assume within-generation market completeness (i.e., the existence of a complete set of contingent claims through which agents of the same generation can insure against their income shocks), while assuming two types of across-

\footnotetext{
${ }^{6}$ See, for example, Telmer (1993), Heaton and Lucas (1997), Bertaut and Haliassos (1997), Cocco, Gomes and Maenhout (2005), Cocco (2005), Polkovnichenko (2004), Campbell et. al (2001), Hu (2005), Viceira (2001), Gomes and Michaelides (2003, 2005, 2008), Yao and Zhang (2005), Storesletten, Telmer and Yaron (2007), and Ball (2008).
} 
generation market incompleteness: a) consumers cannot trade claims against their future income with consumers from another generation, and b) consumers cannot trade with consumers from an unborn generation.

There is a financial market where two types of securities are traded: a (consol) bond and a share of equity (risky asset), both infinitely lived. The consol bond here works as a proxy for long-term government debt. The consol bond is default-free and pays a fixed coupon of 1 unit of the consumption good in every period in perpetuity. Its supply is fixed at $b$ units. The aggregate coupon payment is $b$ in every period and represents a portion of the economy's capital income. $p_{t}^{b}$ is the ex coupon price of bond in period t. Additionally, we estimate the return and the first moment condition as well as the premium of the one-period (twenty-year) discount bond. The one-period bond is in zero net supply. ${ }^{7}$

One perfectly divisible equity share is also traded. The equity is the claim to the net dividend stream $\left\{d_{t}\right\}$ : the sum total of all the private capital income (stocks, corporate bonds, and real estate). Similarly, the ex dividend price of equity in period $t$ is $p_{t}^{e}$. The total supply of equity is fixed at one.

The consumer born in period $t$ receives a low deterministic $w^{0}>0$ wage income in period $t$, stochastic wage income $w_{t+1}^{1}$ when middle-aged in period $t+1$, and zero wage income in period $t+2$ when old. The wage income process of the middle-aged consumer is exogenous in order to avoid modeling the labor-leisure trade-off.

A consumer born in period $t$ starts with zero endowment of the bond and equity. He purchases $x_{t, 0}^{b}$ bonds and $x_{t, 0}^{e}$ shares of equity in period $t$ (when young). The consumer then adjusts his position to $x_{t, 1}^{b}$ and $x_{t, 1}^{e}$ when middle aged. The old consumers sell their bond and stock holdings and consume the proceeds. This means that $x_{t, 2}^{b}=0$, and $x_{t, 2}^{e}=0$. Market clearing in period $t$ then requires that the demand for bonds and

\footnotetext{
${ }^{7}$ The price of this bond is a shadow price, determined by the marginal rate of substitution of the middle-aged consumer. Note that this bond is the true risk-free rate in this economy. Note also that it is not possible to introduce a one-year bond in this setup, since the length of one period is assumed to be twenty years.
} 
equity by the young and the middle-aged consumers equal their fixed supply. Therefore,

$$
x_{t, 0}^{b}+x_{t-1,1}^{b}=b
$$

and similarly,

$$
x_{t, 0}^{e}+x_{t-1,1}^{e}=1
$$

Let $c_{t, j}$ denote the consumptions in period $t+j(j=0,1,2)$ of a consumer born in period $t$. The budget constraint of the consumer born in period $t$ is:

$$
c_{t, 0}+x_{t, 0}^{b} p_{t}^{b}+x_{t, 0}^{e} p_{t}^{e} \leq w^{0}
$$

when young,

$$
c_{t, 1}+x_{t, 1}^{b} p_{t+1}^{b}+x_{t, 1}^{e} p_{t+1}^{e} \leq w_{t+1}^{1}+x_{t, 0}^{b}\left(p_{t+1}^{b}+1\right)+x_{t, 0}^{e}\left(p_{t+1}^{e}+d_{t+1}\right)
$$

when middle-aged, and

$$
c_{t, 2} \leq x_{t, 1}^{b}\left(p_{t+2}^{b}+1\right)+x_{t, 1}^{e}\left(p_{t+2}^{e}+d_{t+2}\right)
$$

when old. Furthermore, we require that $c_{t, 0} \geq 0, c_{t, 1} \geq 0$, and $c_{t, 2} \geq 0$, thus ruling out negative consumption and personal bankruptcy.

There is an increasing sequence $\left\{I_{t}: t=0,1, \ldots\right\}$ of information sets available to consumers in each period $t$. $I_{t}$ contains information about all the past wage income and dividends up to and including period $t$. Furthermore, $I_{t}$ contains the consumption, bond investment, and stock investment histories of all the consumers up to and including period $t-1$. Consumption and investment decisions made in period $t$ depend only on information available in period $t$. A consumption and investment policy of the consumer born in period $t$ is the collection of the $I_{t}$-measurable $\left(c_{t, 0}, x_{t, 0}^{b}, x_{t, 0}^{e}\right)$, the $I_{t+1}$-measurable $\left(c_{t, 1}, x_{t, 1}^{b}, x_{t, 1}^{e}\right)$, and the $I_{t+2}$-measurable $c_{t, 2}$.

The novelty of this paper lies in introducing increasing risk aversion in this setting. Specifically, the consumer born in period $t$ has utility:

$$
E\left(\sum_{i=0}^{2} \beta^{i} u\left(c_{t, i}, \alpha_{i}\right) \mid I_{t}\right),
$$


where $I_{t}$ is the set of all the information available in period $t$, and the period utility function is given by:

$$
u\left(c_{t, i}, \alpha_{i}\right)=\frac{c_{t, i}^{1-\alpha_{i}}-1}{1-\alpha_{i}},
$$

where $\alpha_{i}>0$ is the risk aversion parameter. Consistent with the empirical literature, $\alpha_{i}$ is assumed to vary with the consumer's age: the older consumers exhibit higher risk aversion than the younger ones.

We model the joint process of aggregate income and wages of the middle-aged, $\left(y_{t}, w_{t}^{1}\right)$, as a time-stationary probability distribution where the aggregate income $y_{t}$ is:

$$
y_{t}=w^{0}+w_{t}^{1}+b+d_{t}
$$

In the calibration, $y_{t}$ and $w_{t}^{1}$ assume two values each: $y_{1}, y_{2}$ and $w_{1}^{1}, w_{2}^{1}$. These form four states denoted by $s_{t}=j$, where $j=1, \ldots, 4$. The $4 \times 4$ transition probability matrix is denoted by $\Pi$.

Following Constantinides, Donaldson, and Mehra (2002), we study the borrowingconstrained version of the model economy in which the young generation is effectively excluded from participating in the financial market. ${ }^{8}$ The young earn deterministic low wages and want to smooth their lifetime consumption by borrowing against future wage income, consuming part of the loan, and investing the rest in equity. However, with low wages, and with only human capital as collateral, they are unable to borrow

\footnotetext{
${ }^{8}$ The borrowing constraint assumption may prove unrealistic if the labor income profile is substantially flatter over the life-cycle, or if individuals are faced with a probability of a disastrous labor income shock. In that case, the introduction of uninsurable, persistent, and heteroskedastic labor income shocks would more realistically depict the portfolio choice decision over the life-cycle (see for example, Cocco, Gomes and Maenhout (2005)). We abstract from modeling labor income risk for the following reasons: first, in order to best highlight the role of increasing risk aversion in the borrowingconstraint framework of CDM (2002), we attempt to retain as many features of the baseline CDM model as possible. Second, since our focus is primarily on the across generation heterogeneity (particularly as it relates to preference specifications (IRA)), we downplay within generation heterogeneity (which results from the inclusion of uninsurable labor income risk over the life-cycle). Third, as argued by Cocco, Gomes and Manhout (2005), when allowing for labor income uncertainty, young households are liquidity constrained for the first 10-15 years of their lives and equity investment is low in the presence of heterogeneous (sector-specific) labor income risk or a small probability of disastrous labor income shocks, which suggests that borrowing constraint may obtain even when introducing a more realistic labor income profile.
} 
against future wage income. ${ }^{9}$ Thus, in this borrowing-constrained economy there exists a rational expectations equilibrium in which the young do not participate in the bond and equity markets, i.e., $x_{t, 0}^{b}=0$ and $x_{t, 0}^{e}=0$. This means that in the presence of borrowing constraints, securities are solely priced by the middle-aged investors. ${ }^{10}$

Equilibrium is defined as the set of consumption and investment policies of the consumers born in each period and the bond and stock prices in all periods such that: (i) each consumer maximizes his expected utility taking the price processes as given; (ii) bond and equity markets clear in all periods.

Given the consumption constraints $((2 \mathrm{a})-(2 \mathrm{c}))$ and the borrowing constraint, the optimization problem with respect to $x_{t, 1}^{b}$ and $x_{t, 1}^{e}$ yields the following first order conditions:

$$
u^{\prime}\left(c_{t, 1}\right) p_{t+1}^{b}=E\left(\beta u^{\prime}\left(c_{t, 2}\right)\left(p_{t+2}^{b}+1\right) \mid I_{t}\right)
$$

and

$$
u^{\prime}\left(c_{t, 1}\right) p_{t+1}^{e}=E\left(\beta u^{\prime}\left(c_{t, 2}\right)\left(p_{t+2}^{e}+d_{t+2}\right) \mid I_{t}\right),
$$

where

$$
c_{t, 1}=w_{t+1}^{1}-x_{t, 1}^{b} p_{t+1}^{b}-x_{t, 1}^{e} p_{t+1}^{e}
$$

and

$$
c_{t, 2}=x_{t, 1}^{b}\left(p_{t+2}^{b}+1\right)+x_{t, 1}^{e}\left(p_{t+2}^{e}+d_{t+2}\right) .
$$

The share of the total wealth saved and invested by the middle-aged investor is given by

$$
\Phi_{t, 1}^{s}=\frac{x_{t, 1}^{b} p_{t+1}^{b}+x_{t, 1}^{e} p_{t+1}^{e}}{w_{t+1}^{1}},
$$

\footnotetext{
${ }^{9}$ The borrowing constraint is binding for bonds; the young may not borrow by shorting bonds. They are, however, allowed to short equity, but the short-sale equity constraint is non-binding for the set of parameters chosen to calibrate the model; i.e., the young choose not to short equity.

${ }^{10} \mathrm{It}$ is important to note that in the presence of the borrowing constraint, the model is identical to a two-period OLG economy (without the young). In this case, all investment decisions will occur in the first period, while in the second period the agents retire and consume the assets accumulated in the first period. The implications and findings of this set-up would be identical to what we present in this paper. However, we retain the framework of the three-period OLG model in order to facilitate comparisons with the baseline CDM (2002) model with non-increasing risk aversion.
} 
while the relative shares of the wealth invested in bonds and equity are

$$
\Phi_{t, 1}^{b}=\frac{x_{t, 1}^{b} p_{t+1}^{b}}{w_{t+1}^{1}}
$$

and

$$
\Phi_{t, 1}^{e}=\frac{x_{t, 1}^{e} p_{t+1}^{e}}{w_{t+1}^{1}}
$$

respectively. ${ }^{11}$ Additionally, the shares of the savings/investment that goes into bonds and equity are

$$
\omega_{t, 1}^{b}=\frac{x_{t, 1}^{b} p_{t+1}^{b}}{x_{t, 1}^{b} p_{t+1}^{b}+x_{t, 1}^{e} p_{t+1}^{e}}
$$

and

$$
\omega_{t, 1}^{e}=\frac{x_{t, 1}^{e} p_{t+1}^{e}}{x_{t, 1}^{b} p_{t+1}^{b}+x_{t, 1}^{e} p_{t+1}^{e}}
$$

respectively. $\omega_{t, 1}^{b}$ and $\omega_{t, 1}^{b}$ reflect the investor's choice between the safe and the risky asset as he forms his portfolio.

Using market clearing conditions ((1a)-(1b)), and dropping the time subscripts, the FOCs become:

$$
u^{\prime}\left(c_{1}\right) p^{b}(j)=\beta \sum_{k=1}^{4}\left(u^{\prime}\left(c_{2}\right)\left\{p^{b}(k)+1\right\}\right) \Pi_{j k}
$$

and

$$
u^{\prime}\left(c_{1}\right) p^{e}(j)=\beta \sum_{k=1}^{4}\left(u^{\prime}\left(c_{2}\right)\left\{p^{e}(k)+d(k)\right\}\right) \Pi_{j k}
$$

with

$$
c_{1}=w^{1}(j)-b p^{b}(j)-p^{e}(j)
$$

\footnotetext{
${ }^{11}$ It should be noted that an additional model limitation is that it assumes a fixed supply of assets (bonds and equity) over long periods of time, which is rather unrealistic. There are a number of ways to remedy this issue, which we defer for future work (allowing for across-generation market completeness (inter-generational trading), extending the model to a production economy, or by introducing growth). While the fixed asset supply assumption may be problematic if the focus is specifically on asset returns and portfolio allocations over the life-cycle, here the determinant of consumption/saving and portfolio allocation is the age-dependent "risk-profile" of the agent. As such, our main objective is to analyze the behavior of asset returns, consumption/savings, and portfolio allocations under two different preference assumptions: standard utility (with constant risk aversion) and non-standard preferences which display increasing risk aversion with age
} 
and

$$
c_{2}=b\left(p^{b}(j)+1\right)+p^{e}(j)+d(j)
$$

for each state $j$ of the economy.

Since our utility function is $u\left(c_{t, i}, \alpha_{i}\right)=\frac{c_{t, i}^{1-\alpha_{i}}-1}{1-\alpha_{i}}$, the marginal utilities of the middleaged and old consumers are respectively $u^{\prime}\left(c_{1}\right)=c_{1}^{-\alpha_{1}}$ and $u^{\prime}\left(c_{2}\right)=c_{2}^{-\alpha_{2}}$. Then

$$
\frac{p^{b}(j)}{\left(w^{1}(j)-b p^{b}(j)-p^{e}(j)\right)^{\alpha_{1}}}=\beta \sum_{k=1}^{4} \frac{\left\{p^{b}(k)+1\right\} \Pi_{j k}}{\left(b\left(p^{b}(k)+1\right)+p^{e}(k)+d(k)\right)^{\alpha_{2}}}
$$

and

$$
\frac{p^{e}(j)}{\left(w^{1}(j)-b p^{b}(j)-p^{e}(j)\right)^{\alpha_{1}}}=\beta \sum_{k=1}^{4} \frac{\left\{p^{e}(k)+d(k)\right\} \Pi_{j k}}{\left(b\left(p^{b}(k)+1\right)+p^{e}(k)+d(k)\right)^{\alpha_{2}}}
$$

are the two equations to be estimated. ${ }^{12}$

\section{Calibration}

In order to focus exclusively on the impact of increasing risk aversion on security returns and portfolio choice, we use the same calibration parameters as Constantinides, Donaldson, and Mehra (2002). As such, we limit our discussion here to a summary of the key parameters. ${ }^{13}$

It should be noted that in this three-period overlapping generations framework, one period - which spans one generation - is assumed to represent 20 years. With this (20year one-period) set-up, the subjective discount factor $(\beta)$ is set equal to 0.44 implying an annual discount factor of 0.96 - the standard annual discount factor used in the literature.

The equilibrium joint distribution of the bond and equity returns depends on a set of parameters which are calibrated as in CDM (2002) based on historical observations and

\footnotetext{
${ }^{12}$ The estimation method we employ is Newton-Raphson with 500 iterations.

${ }^{13}$ As argued in Constantinides, Donaldson, and Mehra (2002), there are some difficulties in empirically estimating the moment conditions to calibrate the model, mostly because we are dealing with twenty year aggregates in the context of only a century-long data set. Therefore, the standard errors of the point estimates tend to be rather large. See Constantinides, Donaldson, and Mehra (2002) for a more detailed discussion on these moment conditions.
} 
empirical studies. The key calibrated parameters are: 1) The average share of income going to labor $\left(E\left(w^{1}+w^{0}\right) / E(y)\right)$ is set at $\left.0.65 ; 2\right)$ The average share of income going to the labor of the young, $w^{0} / E(y)$, is set at $\left.0.19 ; 3\right)$ The average share of income going to interest on government debt, $b / E(y)$, is set at $0.03 ; 4)$ The coefficient of variation of the twenty-year wage income of the middle-aged, $\sigma\left(w^{1}\right) / E\left(w^{1}\right)$, is fixed at 0.25 ; 5) The coefficient of variation of the twenty-year aggregate income, $\sigma(y) / E(y)$, is set at 0.20 ; 6) The twenty-year auto-correlations and cross-correlation of the labor income of the middle-aged and the aggregate income $\left(\operatorname{corr}\left(w_{t}^{1}, w_{t-1}^{1}\right), \operatorname{corr}\left(y_{t}, y_{t-1}\right)\right.$, and $\left.\operatorname{corr}\left(y_{t}, w_{t}^{1}\right)\right)$ are set at $0.1 .^{14}$

The transition matrix of the joint Markov process on the wage income of the middleaged consumers and the aggregate income is given by:

$$
\left[\begin{array}{ccccc} 
& \left(y_{1}, w_{1}^{1}\right) & \left(y_{1}, w_{2}^{1}\right) & \left(y_{2}, w_{1}^{1}\right) & \left(y_{2}, w_{2}^{1}\right) \\
\left(y_{1}, w_{1}^{1}\right) & \phi & \pi & \sigma & H \\
\left(y_{1}, w_{2}^{1}\right) & \pi+\Delta & \phi-\Delta & H & \sigma \\
\left(y_{2}, w_{1}^{1}\right) & \sigma & H & \phi-\Delta & \pi+\Delta \\
\left(y_{2}, w_{2}^{1}\right) & H & \sigma & \pi & \phi
\end{array}\right]
$$

where

$$
\phi+\pi+\sigma+H=1 \text {. }
$$

Nine parameters need to be estimated: $y_{1} / E(y), y_{2} / E(y), w_{1}^{1} / E(y), w_{2}^{1} / E(y), \phi, \pi$, $\sigma, H$, and $\Delta$. These are chosen to satisfy the eight moment conditions described above as well as condition (12) while requiring that all matrix entries are positive.

Table 1, from the work of Constantinides, Donaldson, and Mehra (2002), shows the historical mean and standard deviations of the annualized, twenty-year holdingperiod return on the S\&P 500 total return series and on the Ibbotson US Government Treasury Long-Term bond yield. ${ }^{15}$ From Table 1, the real mean equity return is 6-7\%

\footnotetext{
${ }^{14} \mathrm{We}$ also generated results for the following correlation pairs: $\operatorname{corr}\left(y_{t}, w_{t}^{1}\right)=0.1$ and $\operatorname{corr}\left(w_{t}^{1}, w_{t-1}^{1}\right)=\operatorname{corr}\left(y_{t}, y_{t-1}\right)=0.8, \operatorname{corr}\left(y_{t}, w_{t}^{1}\right)=0.8$ and $\operatorname{corr}\left(w_{t}^{1}, w_{t-1}^{1}\right)=\operatorname{corr}\left(y_{t}, y_{t-1}\right)=0.1$, and $\operatorname{corr}\left(y_{t}, w_{t}^{1}\right)=0.8$ and $\operatorname{corr}\left(w_{t}^{1}, w_{t-1}^{1}\right)=\operatorname{corr}\left(y_{t}, y_{t-1}\right)=0.8$. Results from these calibrations were similar to the baseline case with $\operatorname{corr}\left(y_{t}, w_{t}^{1}\right)=0.1$ and $\operatorname{corr}\left(w_{t}^{1}, w_{t-1}^{1}\right)=\operatorname{corr}\left(y_{t}, y_{t-1}\right)=0.1$. They are suppressed for brevity and are available upon request.

${ }^{15}$ Real returns are CPI adjusted. The annualized mean return (for both the equity and bond) is
} 
with a standard deviation of $14-16 \%$; the mean bond real return is about $1 \%$ with a standard deviation of $7 \%$; and the mean equity premium is $5-7 \%$ with a standard deviation of $14-15 \%$. Similar to CDM (2002), since in the model the equity is defined as claim not just to corporate dividends but also to all the risky capital in the economy, the mean equity premium we seek to match is around 3 percent.

\section{Results}

\subsection{The Impact of IRA on Asset Returns and Equity Premium}

The effects of increasing risk aversion on security returns, equity premium, savings, and portfolio shares are presented in Tables 2-9. Results are reported for various combinations of middle aged and old agents risk aversion parameters $\left\{\alpha_{1}, \alpha_{2}\right\}$, ranging from $\{2.00,2.00\}$ to $\{6.00,6.75\} .{ }^{16}$ To highlight the role of $I R A$, for each selected pair, we present results from the CDM (2002) baseline model of constant risk aversion $(C R A)$ (e.g., $\left.\left\{\alpha_{1}, \alpha_{2}\right\}=\{2.00,2.00\}\right)$ and compare them with our increasing risk aversion (IRA) set up where risk aversion increases with age (e.g., $\left.\left\{\alpha_{1}, \alpha_{2}\right\}=\{2.00,2.25\}\right)$. As discussed in Section 3, all reported results are for the following set of calibrated parameters: $E(y)=98,399, w^{0}=19,000, E\left(w^{1}\right)=44,650, \sigma(y) / E(y)=0.20, \sigma\left(w^{1}\right) / E\left(w^{1}\right)=0.25$, $\operatorname{corr}\left(y_{t}, w_{t}^{1}\right)=0.1$, and $\operatorname{corr}\left(w_{t}^{1}, w_{t-1}^{1}\right)=\operatorname{corr}\left(y_{t}, y_{t-1}\right)=0.1$. The one-period discount bond is referred to as the bond. It is in zero net supply. The consol bond, which is in positive net supply, is referred to as the consol.

As a preliminary step, we take a brief look at security returns under constant risk aversion (CRA) as the average level of risk aversion in the economy increases, i.e., as

defined as the sample mean of the $[\log \{20$-year holding period return $\}] / 20$. The annualized standard deviation of the equity (or bond) return is defined as the sample standard deviation of the $[\log \{20$-year holding period return $\}] / \sqrt{20}$. The annualized mean equity premium is defined as the difference of the mean return on equity and the mean return on the bond. The standard deviation of the premium is defined as the sample standard deviation of the $[\{\log \{20$-year nominal equity return $\}$ - $\log \{20$-year nominal bond return $\}] / \sqrt{20}$.

${ }^{16}$ We do not consider the risk aversion of the young since they are effectively shut out of the securities market. The model introduces some form of limited participation since agents participate in the market in two out of the three periods - as savers when middle aged and as dissavers when old. 
we move from the risk-aversion pair $\left\{\alpha_{1}, \alpha_{2}\right\}=\{2.00,2.00\}$ to $\left\{\alpha_{1}, \alpha_{2}\right\}=\{6.00,6.00\}$ (Table 2, columns (i). (iii), (v), (vi) and (ix)). Consistent with theory, as the overall level of risk aversion increases, equity returns rise, bond returns decline, and equity premium increases. Specifically, the equity premium over the bond increases from $1.54 \%$ when $\left\{\alpha_{1}, \alpha_{2}\right\}=\{2.00,2.00\}$ to $3.36 \%$ when $\left\{\alpha_{1}, \alpha_{2}\right\}=\{6.00,6.00\}$. This is in line with expectations: more risk averse investors generally require a higher premium to hold risky assets. At the same time, a higher average risk aversion also implies a higher demand for bonds, which in turn suppresses equilibrium bond returns. The end result is an increase in equity premium and an increase in bond holdings in the financial portfolio.

Next, we focus on the key innovation: the introduction of $I R A$ and its impact on security returns and on the equity premium. We find that for each selected pair (i.e., $\left\{\alpha_{1}, \alpha_{2}\right\}=\{2.00,2.00\}$ vs $\left\{\alpha_{1}, \alpha_{2}\right\}=\{2.00,2.25\}$ ), an increase in risk aversion (relative to the $C R A$ baseline) leads to an increase in both equity and bond returns, and a higher equity premium. The higher equity premium with $I R A$ obtains because old consumers are more risk averse than middle-aged ones $\left(\alpha_{2}>\alpha_{1}\right)$ which raises both equity and bond returns relative to the baseline case $\left(\alpha_{1}=\alpha_{2}\right)$, but the increase in the equity return is larger resulting in higher premium. Overall, the model delivers equity premium values that are consistent with their historical averages even for low levels of risk aversion (i.e., $\{2.00,2.25\})^{17}$

It should be noted that the higher equity premium is obtained by fairly small differences in risk aversion values - for all cases presented $\alpha_{2}$ is only 0.25 higher than $\alpha_{1}$. More importantly, we find that results are driven primarily by the relative difference between the two risk aversion parameters (how much more risk averse old agents are relative to the middle aged) rather than the average risk aversion in the econ-

\footnotetext{
${ }^{17} \mathrm{An}$ undesirable feature of the model is that it produces equity returns, bond returns and standard deviations which are higher than the historical averages. IRA increases both equity and bond returns with the latter exacerbating the risk-free puzzle.
} 
omy (how much more risk averse both cohorts are). Table 3 highlights this point. As seen, $\left\{\alpha_{1}, \alpha_{2}\right\}=\{2.00,2.25\}$ delivers higher equity and bond returns compared to $\left\{\alpha_{1}, \alpha_{2}\right\}=\{6.00,6.25\}$ despite the fact that the average level of risk aversion in the economy is much higher in the second case. This is so because the relative increase in risk aversion is higher under the $\left\{\alpha_{1}, \alpha_{2}\right\}=\{2.00,2.25\}$ scenario (a $12.5 \%$ increase) relative to $\left\{\alpha_{1}, \alpha_{2}\right\}=\{6.00,6.25\}$ case (a $4.10 \%$ increase). Note however that the equity premium with $\left\{\alpha_{1}, \alpha_{2}\right\}=\{6.00,6.25\}$ is higher. In a more extreme case, when risk aversion increases substantially more it is possible to generate a higher equity premium even when the average level of risk aversion is low. For example, the pair $\left\{\alpha_{1}, \alpha_{2}\right\}=\{2.00,2.50\}$ (representing a 50\% increase in risk aversion), produces higher equity, bond and equity premium than $\left\{\alpha_{1}, \alpha_{2}\right\}=\{6.00,6.25\}$. This suggests while the average level of risk aversion in the economy matters, the difference between the two risk aversion parameters (i.e., how much more risk averse agents become as they age) is an even more important driver of our results.

An alternative way at looking at the above results would be to assume the same relative increase in risk aversion for all risk aversion pairs. Table 4 shows results for different levels of risk aversion, where $\alpha_{2}$ increases by $12.5 \%$ compared to $\alpha_{1}$. As expected, for the same relative increase in risk aversion, a higher risk aversion pair produces higher equity return, higher bond return, and higher equity premium. For example, when comparing $\left\{\alpha_{1}, \alpha_{2}\right\}=\{6.00,6.75\}$ with $\left\{\alpha_{1}, \alpha_{2}\right\}=\{2.00,2.25\}$, the equity return with $\left\{\alpha_{1}, \alpha_{2}\right\}=\{6.00,6.75\}$ is $9.6 \%$ higher, the bond return is $4.7 \%$ higher, and the equity premium is $4.9 \%$ higher than when $\left\{\alpha_{1}, \alpha_{2}\right\}=\{2.00,2.25\}$. In both cases, the risk aversion of older agents increased by $12.5 \%$ relative to the previous period, which means that a higher overall level of risk aversion in the economy produces, as expected, higher asset returns and equity premium. 


\subsection{Analyzing the Effects of Increasing Risk Aversion}

Introducing IRA in the baseline model of CDM (2002) of constant (non-increasing) risk aversion, delivers higher equity and bond returns and higher equity premium. The intuition for these results is fairly straightforward: with $I R A$, the agents become even more averse to gambles that play out in the future (when old) so they save less and consume more compared to the $C R A$ scenario. A lower level of savings means that the overall wealth invested in financial market (both in equities and bonds) also declines. On balance, the effect is to increase both equity and bond returns while increasing the equity risk premium.

The IRA reinforces the borrowing constraint effect of the baseline CDM model and produces higher equity returns. Equity returns increase both because the level of savings/investment declines and because the middle-aged cohort knows that it will become more risk averse when old and requires a much higher equity return (relative to bonds) in order to invest in equity given its uncertain future payoffs. Thus, in the case of equity, the IRA reinforces the effect of the borrowing constraint and produces higher equity returns in equilibrium. ${ }^{18}$

At the same time, however, the introduction of IRA leads to an increase in the bond return relative to the baseline $C R A$ model. Middle-aged agents, who will be more risk averse in the future, are now even less willing to give up current consumption for future consumption. Therefore, they demand higher return on the bond (and equity). This

\footnotetext{
${ }^{18} \mathrm{As}$ in CDM (2002), the borrowing constraint increases equity returns because equity returns are driven exclusively by middle-aged agents since the young cannot participate in the market. However, equity does not have the same appeal for the middle-aged as it does for the young because there is no wage uncertainty for the middle-aged. Consumption for this age cohort is highly correlated with equity income which means that equity no longer serves as a hedge against consumption and it requires a higher rate of return for this group.
} 
can be seen by analyzing the stochastic discount factor (SDF) in this economy ${ }^{19}$ :

$$
m_{t+1}=\frac{\beta * u^{\prime}\left(c_{t, 2}\right)}{u^{\prime}\left(c_{t, 1}\right)}=\beta *\left(\frac{c_{t, 2}}{c_{t, 1}}\right)^{-\alpha_{1}} * c_{t, 2}^{\left(\alpha_{1}-\alpha_{2}\right)} .
$$

In the CRA case when $\alpha_{1}=\alpha_{2}$, the $\operatorname{SDF}$ is $\beta *\left(\frac{c_{t, 2}}{c_{t, 1}}\right)^{-\alpha_{1}}$. Thus, the presence of increasing risk aversion $\left(\alpha_{1}<\alpha_{2}\right)$ introduces an additional factor, $c_{t, 2}^{\left(\alpha_{1}-\alpha_{2}\right)}$, which decreases the standard SDF: the individual agent's willingness to shift consumption between middle-age and old-age declines, and the risk-free rate (the inverse of $E(m)$ ) increases. For example, the SDF is lower when $\left\{\alpha_{1}, \alpha_{2}\right\}=\{2.00,2.25\}$ than when $\left\{\alpha_{1}, \alpha_{2}\right\}=\{2.00,2.00\}$.In a sense, IRA and the borrowing constraint have opposite effects on bond returns: while borrowing constraint reduces bond returns (the young cannot borrow at the risk-free rate to invest in equity), IRA raises bond returns (through its impact on the SDF).

One issue arising from our preference specification of increasing risk-aversion is that the stochastic discount factor depends on the absolute level of consumption. This is a potential concern because the model is not in sensitive to scale. To check for the importance of scale in our model, we carried out a number of robustness tests for different levels of risk aversion. Table 5 shows the impact of scale on our results when the average level of income in the economy $(E(y))$ doubles. As seen, the scaling effect has a relatively small impact in our specification: for example, for risk aversion pair $\left\{\alpha_{1}, \alpha_{2}\right\}=\{2.00,2.25\}$, if average income doubles, the equity return goes up by $0.59 \%$, the bond return by $0.41 \%$ and the equity premium over the bond increases only by

\footnotetext{
${ }^{19}$ The middle-aged agents seek to maximize utility over their life-cycle; the difference here is that the marginal utility of consumption differs across the two periods (from middle-aged to old), since attitudes toward risk change with age. More specifically, the intertemporal choice problem for a middle aged consumer is as follows: he equates the loss in utility associated with buying one additional unit of equity (or bond) $\left(p_{t} U^{\prime}\left(c_{t}\right)\right)$ to the discounted expected utility of the additional consumption in the next period $\left(\beta E_{t}\left(p_{t+1}+d_{t+1}\right) U^{\prime}\left(c_{t+1}\right)\right.$. The loss in utility associated with savings/investments when middle aged is: $p_{t} c_{t, 1}^{-\alpha_{1}}$. The gain from this investment results in additional consumption in the next period (when old), and it should be valued with preferences of the old cohort, when the additional equity (or bond) is sold and consumed. The expected value of the incremental utility next period (when old) is: $\beta E_{t}\left\{\left(p_{t+1}+d_{t+1}\right) c_{t, 2}^{-\alpha_{2}}\right\}$. At an optimum, the two are equal, so that the discount factor for the middle aged is given by: $m_{t+1}=\frac{\beta c_{t, 2}^{-\alpha_{2}}}{c_{t, 1}^{-\alpha_{1}}}$.
} 
$0.19 \%$. In fact, a $100 \%$ change in the aggregate income results in a change in security returns and equity premium of less than 5\%, for all risk aversion pairs.

\subsection{The Impact of IRA on Savings and Portfolio Allocation}

The introduction of IRA in an OLG model has significant implication for consumption/saving and portfolio shares. First, to analyze the consumption/saving effect, it helps to present the consumption pattern of each age group and the savings/investment of the middle-aged in all states of the economy. These results are summarized in Table 6. The top panel $\left(\left\{\alpha_{1}, \alpha_{2}\right\}=\{4.00,4.00\}\right)$ illustrates why bonds are attractive despite high equity returns. The consumption of the old age cohort is quite variable, leading the middle-aged to invest some of their wealth in bonds since bonds are a hedge against future consumption variability. The young agents' consumption is the same across all states of the economy (since they simply consume their endowment), while the middle-aged have a relatively smooth consumption pattern.

The bottom panel of Table 6 shows the consumption patterns and middle-aged savings under IRA. As discussed above, middle-aged investors are now even less willing to give up some of their current consumption in return for higher future consumption. In fact, they consume more today and save less for the future despite higher bond and equity returns. ${ }^{20}$ Note also that the variance of middle-aged consumption is much higher under IRA relative to the baseline CDM $C R A$ case.

The results for consumptions/savings for various combinations of risk aversion pairs are presented in Table 7. Assuming $C R A$ and moving from low levels of risk aversion towards higher values, we find that as the average risk aversion in the economy increases (for both middle-aged and old consumers) the level of savings/investment increases modestly. Specifically, two opposing forces determine the level of savings/investment: while more risk averse agents optimally prefer to invest less in risky assets they are also

\footnotetext{
${ }^{20}$ These results may reflect an intertemporal substitution effect rather than a risk aversion effect. DaSilva and Farka (2011) investigate this and explore the impact of IRA on security returns, savings, and portfolio shares in a model economy with recursive preferences (Epstein-Zin).
} 
more prudent and want to accumulate more wealth over the life cycle. Therefore, under the constant risk aversion scenario, the wealth effect dominates the risk aversion effect.

These results change dramatically when increasing risk aversion is introduced. For example, the level of savings declines almost by half when old-age risk aversion increases slightly: from $\$ 12,794$ when $\left\{\alpha_{1}, \alpha_{2}\right\}=\{5.00,5.00\}$ to $\$ 6,795$ when $\left\{\alpha_{1}, \alpha_{2}\right\}=$ $\{5.00,5.25\}$. In addition, with $I R A$, the lowest level of saving is found for $\left\{\alpha_{1}, \alpha_{2}\right\}=$ $\{2.00,2.25\}$ and the highest for $\left\{\alpha_{1}, \alpha_{2}\right\}=\{6.00,6.25\}$ consistent with the view that in the first scenario, agents become "relatively more" risk averse as they age compared to the second case. $^{21}$

Table 8 shows the portfolio decisions of the (middle-aged) investor for different pairs of risk aversion. It summarizes the share of the wealth saved and invested, the share of the savings/investment that goes into equity, and the share of the savings/investment that goes into bonds. Under $C R A$ an increase in the average level of risk aversion in the economy leads to a small increase in the level of savings, an increase in bond holdings $\left(\Phi^{b}\right)$, and a decrease in equity holdings $\left(\Phi^{e}\right)$. For example, as risk aversion increases from $\left\{\alpha_{1}, \alpha_{2}\right\}=\{2.00,2.00\}$ to $\left\{\alpha_{1}, \alpha_{2}\right\}=\{6.00,6.00\}$, savings/investment increase from $\$ 12,362$ ( $27.7 \%$ of total wealth) to $\$ 13,060$ (29.2\% of total wealth), the share of wealth invested in bonds increases from $6 \%$ to $12.6 \%$, while the share of wealth invested in equity drops from $21.6 \%$ to $16.7 \%$. This is in line with empirical evidence which shows that a higher level of risk aversion increases the demand for bonds (safer asset) and reduces the demand for equity.

The introduction of increasing risk aversion has a significant impact on portfolio shares (Table 8). Focusing on comparable pairs (i.e., $\left\{\alpha_{1}, \alpha_{2}\right\}=\{4.00,4.00\}$ vs $\left.\left\{\alpha_{1}, \alpha_{2}\right\}=\{4.00,4.25\}\right)$, the overall share of financial portfolio declines with increasing risk aversion as investors save less and consume more. For example, the share of

\footnotetext{
${ }^{21}$ It should be noted that higher average return may also lead to lower overall savings in the economy, though this is mostly a second order effect (higher consumption by the middle-aged due to increased risk aversion when old is the primary reason for a reduced saving rate which leads to higher asset returns).
} 
wealth saved and invested declines from $28.0 \%$ with $\left\{\alpha_{1}, \alpha_{2}\right\}=\{4.00,4.00\}$ to $12.7 \%$ with $\left\{\alpha_{1}, \alpha_{2}\right\}=\{4.00,4.25\}$. In addition, both the share of wealth invested in bonds and the share of wealth invested in equity decline, with the decrease in equity share exceeding the bonds'. For example, the share of wealth invested in equity declines from $17.5 \%$ to $5.7 \%$ while the bonds' share decreases from $10.5 \%$ to around $7.0 \%$ (going from $\{4.00,4.00\}$ to $\{4.00,4.25\})$.

These findings suggest that with IRA not only does the overall share of wealth in financial assets decline, but the composition of the financial portfolio also changes as wealth is shifted away from the risky and into the safer asset. Out of his savings, the middle aged investor invests only $44.8 \%$ in equity with $\operatorname{IR} A(\{4.00,4.25\})$ compared to $62.4 \%$ in the $C R A$ benchmark case $(\{4.00,4.00\})$. Alternatively, the portfolio share of bonds increases from $37.6 \%$ to $55.2 \%$. This reflects the desire to move away from risky assets and into safer ones as the agents become more risk averse with age. Recall that the bond is appealing to the investor, despite its lower return, because it works as a hedge against future consumption variability. With increasing risk aversion, the appeal of the bond as a hedge against future consumption variation increases leading agents to invest a larger share of savings in bonds.

It should be noted that the introduction of $I R A$ produces more realistic portfolio shares compared to $C R A$, for each pair of risk aversion parameters. Empirical evidence has consistently found that the share of the risky asset in the portfolio is around $50 \%$ (Poterba and Samwick (2001), Bertraut and Starr-McCluer (2002), Ameriks and Zeldes (2004)). With CRA, the portfolio share of equity in our model ranges from $57 \%-78 \%$, depending on the average level of risk aversion in the economy (Table 8), which exceeds empirical estimates. When $I R A$ is introduced, equity shares appear more in line with the empirical evidence, ranging from $45 \%-53 \%$.

As in the previous section, it is instructive to analyze the behavior of portfolio allocation for risk aversion pairs that display the same relative increase in risk aversion. 
Results from this exercise are presented in Table 9 where risk aversion increases by $12.5 \%$ for all risk aversion pairs. As expected, when risk aversion from middle-aged to old increases by the same amount, an increase in the average (overall) risk aversion in the economy leads to an increased investment in bonds and a decrease in the share of wealth invested in equity. For example, as the overall level of risk aversion increases from $\left\{\alpha_{1}, \alpha_{2}\right\}=\{2.00,2.25\}$ to $\left\{\alpha_{1}, \alpha_{2}\right\}=\{4.00,4.50\}$, the share of wealth invested in bonds increases from $3.09 \%$ to $3.9 \%$, while the share of wealth invested in equity declines from $3.49 \%$ to $1.45 \%$. This is similar to the $C R A$ baseline case presented earlier (Table 7 ), when an increase in the overall level of risk aversion causes a rebalancing of portfolio allocation away from equity and towards safer assets. Interestingly, unlike the $C R A$ specification, the level of savings/investments with IRA declines modestly as we move from lower risk aversion pairs towards higher levels of risk aversion. This indicates that in the presence of $I R A$, the wealth accumulation that results from increased prudence at higher levels of risk aversion is dominated by the effect of increasing risk aversion from middle-aged to old.

In sum, the model with increasing risk aversion produces higher security returns (equity and bond) and standard deviations. Equity return increases significantly more than bond returns, thus easily matching the US equity premium. The overall level of savings/investment in the economy decreases and the composition of the financial portfolio also changes as wealth is shifted away from the risky and into the safer asset (despite higher equity returns).

\section{Conclusions}

This paper suggests a new approach to asset pricing and portfolio allocation, one that takes into consideration the vast body of empirical research linking the agents' level of risk aversion coefficient to their age. We incorporate increasing risk aversion $(I R A)$ in the three-period overlapping generations exchange economy of Constantinides, Donald- 
son, and Mehra (CDM) (2002) with borrowing constraints. We highlight the effect of IRA by assuming that older agents are more risk averse than middle-aged ones while retaining key features of the CDM (2002) framework. This setup allows us to investigate the impact of $I R A$ on security returns, level of savings and portfolio allocation, and compare this with the baseline economy of CDM with non-increasing risk aversion. Our IRA specification produces interesting and significant results that are generally consistent with US data without assuming unreasonable levels of risk aversion.

We find that an increase in risk aversion leads to an increase in equity and bond returns. However, equity returns increase by considerably more than bond returns, which produces a higher equity premium. IRA drives the behavior of asset returns: agents become more risk averse towards gambles that play out in the future which means that they consume more and save/invest less. A lower level of savings implies that the overall wealth invested in financial market (both in equity and bonds) also declines, which drives up both equity and bond returns. IRA has an additional second order effect on equity returns because the middle-aged agents, who know they will become more risk averse when they age, require a higher equity return (relative to the risk-free rate) in order to invest in the risky asset given its uncertain future payoffs.

The introduction of IRA has also significant implication for consumption/saving and portfolio shares. We find that, with IRA, the overall share of wealth invested in both equity and bonds declines with the decrease in equity investment exceeding the decline in bond investment. This suggests that IRA reduces not only the overall share of wealth in the financial assets, but tilts the composition of the financial portfolio as wealth is shifted away from the risky asset and into the safer one. In addition, IRA delivers portfolio shares of the risky asset that match the US data: the equity share in the portfolio is in the range of $45 \%-53 \%$.

Our findings are driven by fairly small increases in risk aversion values from middleaged to old. More importantly, what matters the most is the relative difference between 
the two risk aversion parameters (how much more risk averse old agents are relative to the middle aged) rather than the average risk aversion in the economy (how much more risk averse both cohorts are).

This study looks at the effect of increasing risk aversion within the context of a simple OLG framework and finds that it has important implications for security returns and portfolio allocations. Nonetheless, the model abstracts from some features that may enrich its results. For example, the lack of labor income risk eliminates the precautionary savings motive which would add more realism to the model. However, this paper should be considered as a first attempt at introducing a type of preference modification (increasing risk aversion with age) which accommodates recent empirical evidence. One interesting generalization would be to introduce uninsurable labor income shocks in this framework or separate the effect of increasing risk aversion from the intertemporal rate of substitution. Alternatively, the relaxation of the borrowing constraint may highlight more fully the role of increasing risk aversion on the level of savings, security returns, and household portfolio behavior. 


\section{References}

[1] Abel, A. B., 2003, "The Effects of a Baby Boom on Stock Prices and Capital Accumulation in the Presence of Social Security," Econometrica, 71, 551-578.

[2] Ameriks, J., and S. Zeldes, 2004, "How Do Household Portfolio Shares Vary with Age?," Columbia Business School Working Paper.

[3] Andersson, B., 2001, "Portfolio Allocation over the Life Cycle: Evidence from Swedish Household Data," Uppsala University Working Paper Series.

[4] Bakshi, G. S., and Z. Chen, 1994, "Baby Boom, Population Aging, and Capital Markets," The Journal of Business, 67, 165-202.

[5] Ball, S., 2008, "Stock Market Participation, Portfolio Choice and Pensions over the Life-Cycle," Working Paper.

[6] Bansal, R., and A. Yaron, 2004, "Risks for the Long Run: A Potential Resolution of Asset Pricing Puzzles," The Journal of Finance, 59, 1481-1509.

[7] Barro, R., 2006, "Rare Disasters and Asset Markets in the Twentieth Century," Quarterly Journal of Economics, 121, 832-866.

[8] Bellante, D., and R. P. Saba, 1986, "Human Capital and Life-Cycle Effects on Risk Aversion," Journal of Financial Research, 9, 41-51.

[9] Bertraut, C., and M. Haliassos, 1997, "Precautionary Portfolio Behavior from a Life Cycle Perspective," Journal of Economic Dynamics and Control, 21, 1511-1542.

[10] Bertraut C., and M. Starr-McCluer, 2002, "Household Portfolios in the United States," in Guiso L, Haliassos M and Jappelli T, Household Portfolios, MIT Press.

[11] Brooks, R., 2000, "What Will Happen to Financial Markets When the Baby Boomers Retire?," IMF Working Paper 00/18.

[12] Campbell, J., and J. Cochrane, 1999, "By Force of Habit: A Consumption Based Explanation of Aggregate Stock Market Behavior," Journal of Political Economy, 107, 205-251.

[13] Campbell, J., J. Cocco, F. Gomes, and P. Maenhout, 2001, "Investing Retirement Wealth: A Life Cycle Model," in Campbell J, and Feldstein M, Risk Aspects of Social Security Reform, University of Chicago Press.

[14] Cocco, J., 2005, "Portfolio Choice in the Presence of Housing," Review of Financial Studies, 18, 535-567. 
[15] Cocco, J., F. Gomes, and P. Maenhout, 2005, "Portfolio Choice over the Life Cycle," Review of Financial Studies, 18, 491-533.

[16] Constantinides, G. M., 1990, "Habit Formation: A Resolution of the Equity Premium Puzzle," Journal of Political Economy, 98, 519-543.

[17] Constantinides, G. M., J. B. Donaldson, and R. Mehra, 2002, "Junior Can't Borrow: A New Perspective on the Equity Puzzle," Quarterly Journal of Economics, $117,269-296$.

[18] DaSilva, A., and C. I. Giannikos, 2006, "Higher Risk Aversion in Older Agents: Its Asset Pricing Implications," Columbia University and City University of New York, Baruch College Working Paper.

[19] DaSilva, A., and M. Farka, 2011, "Epstein-Zin Preferences in an Overlapping Generations Model: Implications for Asset Pricing," California State University, Fullerton Working Paper.

[20] DaSilva, A., M. Farka, and C. I. Giannikos, 2011, "Habit Formation in an Overlapping Generations Model with Borrowing Constraints," European Financial Management, forthcoming.

[21] Davis, E. P., and C. Li, 2003, "Demographics and Financial Asset Prices in the Major Industrial Economies," Brunel University-West London Working Paper.

[22] Epstein, L., and S. Zin, 1990, "First-Order' Risk Aversion and the Equity Premium Puzzle," Journal of Monetary Economics, 26, 387-407.

[23] Fagereng, A., 2009, "Household Portfolio Allocation and Age," European University Institute, Working Paper.

[24] Geanakoplos, J., M. Magill, and M. Quinzii, 2004, "Demography and the Long-run Predictability of the Stock Market," Brookings Papers on Economic Activities, 1, 241-325.

[25] Gomes, F., and A. Michaelides, 2003, "Portfolio Choice with Internal Habit Formation: A Life Cycle Model with Uninsurable Labor Income Risk," Review of Economic Dynamics, 6, 729-766.

[26] Gomes, F., and A. Michaelides, 2005, "Optimal Life-Cycle Asset Allocation: Understanding the Empirical Evidence," Journal of Finance, 869-904.

[27] Gomes, F., and A. Michaelides, 2008, "Asset Pricing with Limited Risk Sharing and Heterogeneous Agents," Review of Financial Studies, 21, 415-448. 
[28] Goyal, A., 2004, "Demographics, Stock Market Flows, and Stock Returns," Journal of Financial and Quantitative Analysis, 34, 115-142.

[29] He, H., and D. Modest, 1995, "Market Frictions and Consumption-Based Asset Pricing," Journal of Political Economy, 103, 94-117.

[30] Heaton, J., and D. Lucas, 1997, "Market Frictions, Savings Behavior, and Portfolio Choice," Macroeconomic Dynamics, 1, 76-101.

[31] Hu, X., 2005, "Portfolio Choices for Homeowners," Journal of Urban Economics, $58,114-136$.

[32] Jianakoplos, N. A., and A. Bernasek, 1998, "Are Women More Risk Averse?" Economic Inquiry, 36, 620-630.

[33] Lee, H., and S. Hanna, 1995, "Investment Portfolios and Human Wealth," Financial Counseling and Planning, 6, 147-152.

[34] McCarthy, D., 2004, "Household Portfolio Allocation: A Review of the Literature," Working Paper.

[35] McGrattan, E., and E. C. Prescott, 2003, "Average Debt and Equity Returns: Puzzling?," American Economic Review Papers and Proceedings, 93, 392-397.

[36] Mehra, R., and E. C. Prescott, 1985, "The Equity Premium: A Puzzle," Journal of Monetary Economics, 15, 145-161.

[37] Merton, R. C., 1971, "Optimum Consumption and Portfolio Rules in a Continuous Time Model," Journal of Economic Theory, 3, 373-413.

[38] Morin, R., and A. F. Suarez, 1983, "Risk Aversion Revisited," The Journal of Finance, 38, 1201-1216.

[39] Palsson, A-M., 1996, "Does the Degree of Relative Risk Aversion Vary with Household Characteristics?," Journal of Economic Psychology, 17, 771-787.

[40] Polkovnichenko, V., 2004, "Limited Stock Market Participation and the Equity Premium," Finance Research Letters, 1, 24-34.

[41] Poterba, J. M., 2001, "Demographic Structure and Asset Returns," Review of Economics and Statistics, 83, 565-584.

[42] Poterba, J. M., 2004, "Impact of Population Aging on Financial Markets in Developed Countries," Federal Reserve Bank of Kansas City - Economic Review, 89, 43-53. 
[43] Poterba, J. M., and A. Samwick, 2001, "Household Portfolio Allocation Over the Life-Cycle," Aging Issues in the United States and Japan, Chicago, IL: University of Chicago Press, 65-103.

[44] Riley, W. B., and K. V. Chow, 1992, "Asset Allocation and Individual Risk Aversion," Financial Analysts Journal, 48(6), 32-37.

[45] Rietz, T. A., 1988, "The Equity Risk Premium: A Solution," Journal of Monetary Economics, 22, 117-131.

[46] Samuelson, P. A., 1969, "Lifetime Portfolio Selection by Dynamic Stochastic Programming," Review of Economics and Statistics, 51, 239-246.

[47] Storesletten, K., C. Telmer, and A. Yaron, 2007, "Asset Pricing with Idiosyncratic Risk and Overlapping Generations," Review of Economic Dynamics, 10, 519-548.

[48] Sung, J., and S. Hanna, 1996, "Factors Related to Risk Tolerance," Financial Counseling and Planning, 7, 11-20.

[49] Telmer, C., 1993, "Asset-Pricing Puzzles and Incomplete Markets," Journal of Finance, 48, 1803-1832.

[50] Viceira, L., 2001, "Optimal Portfolio Choice for Long-Horizon Investors with Nontradable Labor Income," Journal of Finance, 55, 1163-1198.

[51] Wang, H., and S. Hanna, 1997, "Does risk tolerance decrease with age?," Financial Counseling and Planning, 8, 27-31.

[52] Weil, P., 1989, "The Equity Premium Puzzle and the Risk-Free Rate Puzzle," Journal of Monetary Economics, 24, 401-421.

[53] Yao, R., and H. H. Zhang, 2005, "Optimal Consumption and Portfolio Choices with Risky Housing and Borrowing Constraints," The Review of Financial Studies, 18, 197-239.

[54] Yoo, P. S., 1994, "Age Dependent Portfolio Selection," Federal Reserve Bank of St. Louis Working Paper 94-003A. 
Table 1

Historical U.S. Real Returns

\begin{tabular}{|c|c|c|c|c|c|c|}
\hline & \multicolumn{3}{|c|}{ 1/1889-12/19999 } & \multicolumn{3}{|c|}{ 1/1926-12/19999 } \\
\hline & Equity & Bond & Premium & Equity & Bond & Premium \\
\hline Mean & 6.15 & 0.82 & 5.34 & 6.71 & 0.14 & 6.58 \\
\hline Standard Deviation & 13.95 & 7.40 & 14.32 & 15.79 & 7.25 & 15.21 \\
\hline
\end{tabular}

Notes

This table is a replica of Table 1 in Constantinides, Donaldson, and Mehra (2002). It shows the mean and standard deviations of the annualized, twenty-year holding-period return on the S\&P 500 total return series and on the Ibbotson U.S. Government Treasury Long-Term bond yield. Real returns are CPI adjusted. The annualized mean return (for both the equity and bond) is defined as the sample mean of the $[\log \{20$-year holding period return $\}] / 20$. The annualized standard deviation of the equity (or bond) return is defined as the sample standard deviation of the $[\log \{20$-year holding period return $\}] / \sqrt{20}$. The annualized mean equity premium is defined as the difference of the mean return on equity and the mean return on the bond. The standard deviation of the premium is defined as the sample standard deviation of the $[\{\log \{20$-year nominal equity return $\}-\log \{20$-year nominal bond return $\}] / \sqrt{20}$. 
Table 2

Security Returns and Equity Premium: Comparisons between Increasing and Constant Risk Aversion

\begin{tabular}{|c|c|c|c|c|c|c|c|c|c|c|}
\hline & $i$ & $i i$ & $i i i$ & $i v$ & $v$ & $v i$ & $v i i$ & viii & $i x$ & $x$ \\
\hline$\alpha_{1}$ & 2.00 & 2.00 & 3.00 & 3.00 & 4.00 & 4.00 & 5.00 & 5.00 & 6.00 & 6.00 \\
\hline$\alpha_{2}$ & 2.00 & 2.25 & 3.00 & 3.25 & 4.00 & 4.25 & 5.00 & 5.25 & 6.00 & 6.25 \\
\hline Mean Equity Return & 6.86 & 13.77 & 7.49 & 13.15 & 7.95 & 12.65 & 8.25 & 12.21 & 8.42 & 11.83 \\
\hline Std. of Equity Return & 16.42 & 27.71 & 18.60 & 27.60 & 20.56 & 28.10 & 22.04 & 28.67 & 23.04 & 29.12 \\
\hline Mean Bond Return & 5.32 & 9.93 & 5.21 & 9.06 & 5.13 & 8.47 & 5.08 & 8.00 & 5.06 & 7.63 \\
\hline Std. of Bond Return & 10.52 & 20.95 & 12.48 & 21.64 & 13.73 & 21.95 & 14.67 & 22.28 & 15.40 & 22.57 \\
\hline Mean Equity Premium/Bond & 1.54 & 3.83 & 2.29 & 4.09 & 2.83 & 4.18 & 3.17 & 4.21 & 3.36 & 4.20 \\
\hline Std. of Equity Premium/Bond & 15.40 & 23.83 & 18.29 & 25.22 & 20.62 & 27.29 & 22.35 & 29.10 & 23.57 & 30.42 \\
\hline Mean Consol Return & 4.73 & 8.73 & 4.28 & 7.19 & 3.99 & 6.32 & 3.83 & 5.78 & 3.75 & 5.43 \\
\hline Std. of Consol Return & 12.75 & 21.64 & 15.55 & 22.84 & 17.21 & 23.76 & 18.31 & 24.59 & 19.11 & 25.23 \\
\hline Mean Equity Premium/Consol & 2.13 & 5.04 & 3.22 & 5.96 & 3.97 & 6.33 & 4.42 & 6.43 & 4.67 & 6.39 \\
\hline Std. of Equity Premium/Consol & 18.24 & 29.98 & 21.47 & 30.07 & 24.01 & 30.28 & 25.71 & 30.43 & 26.70 & 30.49 \\
\hline
\end{tabular}

Notes

This table presents the effects of risk aversion on security returns and on the equity premium. Results are reported for $C R R A$ and IRRA. Results are derived from the following calibration parameters: $E(y)=98,399, w^{0}=19,000 E\left(w^{1}\right)=44,650, \sigma(y) / E(y)=0.20, \sigma\left(w^{1}\right) / E\left(w^{1}\right)=0.25$, $\operatorname{corr}\left(y, w^{1}\right)=0.1$, and $\operatorname{corr}\left(w^{1}, w^{1}\right)=\operatorname{corr}(y, y)=0.1$. The correlation between the middle-aged wage and the dividend is $\operatorname{corr}\left(w^{1}, d\right)=-0.4239$, whereas the long-run probabilities are: $P_{1}=0.275 ; P_{2}=0.225 ; P_{3}=0.225$ and $P_{4}=0.275$. 
Table 3

Security Returns/Equity Premium: Increasing vs. Constant Risk Aversion (Different Relative Increase in Risk Aversion)

\begin{tabular}{l|ccc|cc}
\hline \hline & $\boldsymbol{i}$ & $\boldsymbol{i i}$ & iii & iv & $\boldsymbol{v}$ \\
\hline \hline \multicolumn{1}{c|}{$\boldsymbol{\alpha}_{\boldsymbol{I}}$} & $\mathbf{2 . 0 0}$ & $\mathbf{2 . 0 0}$ & $\mathbf{2 . 0 0}$ & $\mathbf{6 . 0 0}$ & $\mathbf{6 . 0 0}$ \\
\multicolumn{1}{c|}{$\boldsymbol{\alpha}_{2}$} & $\mathbf{2 . 0 0}$ & $\mathbf{2 . 2 5}$ & $\mathbf{2 . 5 0}$ & $\mathbf{6 . 0 0}$ & $\mathbf{6 . 2 5}$ \\
\hline Mean Equity Return & $\mathbf{6 . 8 6}$ & $\mathbf{1 3 . 7 7}$ & $\mathbf{2 3 . 2 4}$ & $\mathbf{8 . 4 2}$ & $\mathbf{1 1 . 8 3}$ \\
Std. of Equity Return & 16.42 & 27.71 & 38.55 & 23.04 & 29.12 \\
Mean Bond Return & $\mathbf{5 . 3 2}$ & $\mathbf{9 . 9 3}$ & $\mathbf{1 6 . 0 0}$ & $\mathbf{5 . 0 6}$ & $\mathbf{7 . 6 3}$ \\
Std. of Bond Return & 10.52 & 20.95 & 30.87 & 15.40 & 22.57 \\
Mean Equity Premium/Bond & $\mathbf{1 . 5 4}$ & $\mathbf{3 . 8 3}$ & $\mathbf{7 . 2 3}$ & $\mathbf{3 . 3 6}$ & $\mathbf{4 . 2 0}$ \\
Std. of Equity Premium/Bond & 15.40 & 23.83 & 28.68 & 23.57 & 30.42 \\
Mean Consol Return & $\mathbf{4 . 7 3}$ & $\mathbf{8 . 7 3}$ & $\mathbf{1 5 . 0 8}$ & $\mathbf{3 . 7 5}$ & $\mathbf{5 . 4 3}$ \\
Std. of Consol Return & 12.75 & 21.64 & 29.89 & 19.11 & 25.23 \\
Mean Equity Premium/Consol & $\mathbf{2 . 1 3}$ & $\mathbf{5 . 0 4}$ & $\mathbf{8 . 1 6}$ & $\mathbf{4 . 6 7}$ & $\mathbf{6 . 3 9}$ \\
Std. of Equity Premium/Consol & 18.24 & 29.98 & 34.23 & 26.70 & 30.49 \\
\hline \hline
\end{tabular}

Notes

This table shows the impact of the relative difference in risk aversion parameters on security returns and on the equity premium. Results are derived from the following calibration parameters: $E(y)=98,399$, $w^{0}=19,000 E\left(w^{1}\right)=44,650, \sigma(y) / E(y)=0.20, \sigma\left(w^{1}\right) / E\left(w^{1}\right)=0.25, \operatorname{corr}\left(y, w^{1}\right)=0.1$, and $\operatorname{corr}\left(w^{1}, w^{1}\right)=\operatorname{corr}(y, y)=0.1$. The correlation between the middle-aged wage and the dividend is $\operatorname{corr}\left(w^{1}, d\right)=-0.4239$, whereas the long-run probabilities are: $P_{1}=0.275 ; P_{2}=0.225 ; P_{3}=0.225$ and $P_{4}=0.275$. 
Table 4

Security Returns/Equity Premium: Increasing vs. Constant Risk Aversion (Same Relative Increase in Risk Aversion)

\begin{tabular}{l|c|c|c|c|c}
\hline \hline & $\boldsymbol{i}$ & $\boldsymbol{i i}$ & $\boldsymbol{i i i}$ & $\boldsymbol{i v}$ & $\boldsymbol{v}$ \\
\hline \hline & $\mathbf{2 . 0 0}$ & $\mathbf{3 . 0 0}$ & $\mathbf{4 . 0 0}$ & $\mathbf{5 . 0 0}$ & $\mathbf{6 . 0 0}$ \\
& $\mathbf{2 . 2 5}$ & $\mathbf{3 . 3 7 5}$ & $\mathbf{4 . 5 0}$ & $\mathbf{5 . 6 2 5}$ & $\mathbf{6 . 7 5}$ \\
\hline Mean Equity Return & $\mathbf{1 3 . 7 7}$ & $\mathbf{1 6 . 9 5}$ & $\mathbf{1 9 . 4 9}$ & $\mathbf{2 1 . 6 2}$ & $\mathbf{2 3 . 3 7}$ \\
Std. of Equity Return & 27.71 & 32.82 & 38.11 & 43.62 & 48.76 \\
Mean Bond Return & $\mathbf{9 . 9 3}$ & $\mathbf{1 1 . 5 2}$ & $\mathbf{1 2 . 8 3}$ & $\mathbf{1 3 . 8 2}$ & $\mathbf{1 4 . 6 0}$ \\
Std. of Bond Return & 20.95 & 27.56 & 32.48 & 36.45 & 39.92 \\
Mean Equity Premium/Bond & $\mathbf{3 . 8 3}$ & $\mathbf{5 . 4 3}$ & $\mathbf{6 . 6 6}$ & $\mathbf{7 . 7 9}$ & $\mathbf{8 . 7 7}$ \\
Std. of Equity Premium/Bond & 23.83 & 27.42 & 30.69 & 35.04 & 40.29 \\
Mean Consol Return & $\mathbf{8 . 7 3}$ & $\mathbf{9 . 3 0}$ & $\mathbf{9 . 8 2}$ & $\mathbf{1 0 . 2 9}$ & $\mathbf{1 0 . 7 5}$ \\
Std. of Consol Return & 21.64 & 26.80 & 30.52 & 33.89 & 37.26 \\
Mean Equity Premium/Consol & $\mathbf{5 . 0 4}$ & $\mathbf{7 . 6 5}$ & $\mathbf{9 . 6 7}$ & $\mathbf{1 1 . 3 3}$ & $\mathbf{1 2 . 6 2}$ \\
Std. of Equity Premium/Consol & 29.98 & 32.05 & 32.10 & 32.50 & 33.44 \\
\hline \hline
\end{tabular}

Notes

This table shows security returns and equity premium assuming that risk aversion increases by the same proportion across all risk aversion pairs. Results are derived from the following calibration parameters: $E(y)=98,399, w^{0}=19,000 E\left(w^{1}\right)=44,650, \sigma(y) / E(y)=0.20, \sigma\left(w^{1}\right) / E\left(w^{1}\right)=0.25$, $\operatorname{corr}\left(y, w^{1}\right)=0.1$, and $\operatorname{corr}\left(w^{1}, w^{1}\right)=\operatorname{corr}(y, y)=0.1$. The correlation between the middle-aged wage and the dividend is $\operatorname{corr}\left(w^{1}, d\right)=-0.4239$, whereas the long-run probabilities are: $P_{1}=0.275 ; P_{2}=0.225$; $P_{3}=0.225$ and $P_{4}=0.275$. 
Table 5

Effects of Scale: IRA and Security Returns/Equity Premium

\begin{tabular}{l|cc|cc|cc}
\hline \hline & $\boldsymbol{i}$ & $\boldsymbol{i i}$ & $\boldsymbol{i i i}$ & $\boldsymbol{i v}$ & $\boldsymbol{v}$ & $\boldsymbol{v} \boldsymbol{i}$ \\
\hline \hline & 2.00 & $\mathbf{2 . 0 0}$ & $\mathbf{3 . 0 0}$ & $\mathbf{3 . 0 0}$ & $\mathbf{4 . 0 0}$ & $\mathbf{4 . 0 0}$ \\
& $\mathbf{2 . 2 5}$ & $\mathbf{2 . 2 5}$ & $\mathbf{3 . 0 0}$ & $\mathbf{3 . 2 5}$ & $\mathbf{4 . 0 0}$ & 4.25 \\
\hline Mean Aggregate Income (Y) & $\mathbf{9 8 , 3 9 9}$ & $\mathbf{1 9 6 , 7 9 8}$ & $\mathbf{9 8 , 3 9 9}$ & $\mathbf{1 9 6 , 7 9 8}$ & $\mathbf{9 8 , 3 9 9}$ & $\mathbf{1 9 6 , 7 9 8}$ \\
Mean Wage Income of the Middle-aged & $\mathbf{4 4 , 6 5 0}$ & $\mathbf{8 9 , 3 0 0}$ & $\mathbf{4 4 , 6 5 0}$ & $\mathbf{8 9 , 3 0 0}$ & $\mathbf{4 4 , 6 5 0}$ & $\mathbf{8 9 , 3 0 0}$ \\
Mean Equity Return & $\mathbf{1 3 . 7 7}$ & $\mathbf{1 4 . 3 6}$ & $\mathbf{1 2 . 6 5}$ & $\mathbf{1 3 . 0 6}$ & $\mathbf{1 1 . 8 3}$ & $\mathbf{1 2 . 1 3}$ \\
Std. of Equity Return & 27.71 & 28.53 & 28.10 & 28.66 & 29.12 & 29.61 \\
Mean Bond Return & $\mathbf{9 . 9 3}$ & $\mathbf{1 0 . 3 4}$ & $\mathbf{8 . 4 7}$ & $\mathbf{8 . 7 7}$ & $\mathbf{7 . 6 3}$ & $\mathbf{7 . 8 6}$ \\
Std. of Bond Return & 20.95 & 21.78 & 21.95 & 22.69 & 22.57 & 23.22 \\
Mean Equity Premium/Bond & $\mathbf{3 . 8 3}$ & $\mathbf{4 . 0 2}$ & $\mathbf{4 . 1 8}$ & $\mathbf{4 . 2 9}$ & $\mathbf{4 . 2 0}$ & $\mathbf{4 . 2 7}$ \\
Std. of Equity Premium/Bond & 23.83 & 24.39 & 27.29 & 27.68 & 30.42 & 30.93 \\
Mean Consol Return & $\mathbf{8 . 7 3}$ & $\mathbf{9 . 1 3}$ & $\mathbf{6 . 3 2}$ & $\mathbf{6 . 5 4}$ & $\mathbf{5 . 4 3}$ & $\mathbf{5 . 5 9}$ \\
Std. of Consol Return & 21.64 & 22.27 & 23.76 & 24.26 & 25.23 & 25.73 \\
Mean Equity Premium/Consol & $\mathbf{5 . 0 4}$ & $\mathbf{5 . 2 3}$ & $\mathbf{6 . 3 3}$ & $\mathbf{6 . 5 2}$ & $\mathbf{6 . 3 9}$ & $\mathbf{6 . 5 5}$ \\
Std. of Equity Premium/Consol & 29.98 & 30.56 & 30.28 & 30.54 & 30.49 & 30.66 \\
\hline \hline
\end{tabular}

Notes

This table shows the effects of scale on security returns and equity premium for different pairs of risk aversion. Results are compared across two different scales, assuming the level of aggregate income in the economy doubles (i.e., $E(y)=98,399, E\left(w^{1}\right)=44,650$ versus $\left.E(y)=196,798 E\left(w^{1}\right)=89,300\right)$. The rest of calibration parameters are as follows: $\sigma(y) / E(y)=0.20, \sigma\left(w^{1}\right) / E\left(w^{1}\right)=0.25, \operatorname{corr}\left(y, w^{1}\right)=0.1$, and $\operatorname{corr}\left(w^{1}, w^{1}\right)=\operatorname{corr}(y, y)=0.1$. The correlation between the middle-aged wage and the dividend is $\operatorname{corr}\left(w^{1}, d\right)=-0.4239$, whereas the long-run probabilities are: $P_{1}=0.275 ; P_{2}=0.225 ; P_{3}=0.225$ and $P_{4}=0.275$. 
Table 6

\section{Consumption and Savings/Investments Across Different States}

(CRA and IRA)

\begin{tabular}{|c|c|c|c|c|c|}
\hline & $\alpha_{1}=$ & $\begin{array}{l}\text { Panel a } \\
00 \& \alpha_{2}\end{array}$ & $=4.00$ & \multirow[b]{2}{*}{ State 4} & \multirow[b]{2}{*}{ Average } \\
\hline & State 1 & State 2 & State 3 & & \\
\hline Middle-Aged Consumption & 38,768 & 34,430 & 26,821 & 27,979 & 32,137 \\
\hline Old Consumption & 60,432 & 25,168 & 72,379 & 31,619 & 47,262 \\
\hline Young Consumption & 19,000 & 19,000 & 19,000 & 19,000 & 19,000 \\
\hline Savings/Investment & 17,082 & 21,420 & 6,629 & 5,471 & 12,513 \\
\hline EquityInvestment & 14,430 & 8,683 & 2,773 & 4,607 & 7,813 \\
\hline Bond Investment & 2,652 & 12,737 & 3,856 & 864 & 4,700 \\
\hline Mean Equity Return & 5.07 & 4.93 & 11.54 & 10.38 & 7.95 \\
\hline Mean Bond Return & 3.10 & -1.04 & 4.53 & 8.53 & 3.99 \\
\hline \multirow[t]{3}{*}{ Mean Equity Premium } & 1.97 & 5.97 & 7.01 & 1.85 & 3.96 \\
\hline & \multicolumn{3}{|c|}{$\alpha_{1}=4.00 \& \alpha_{2}=4.25$} & & \\
\hline & State 1 & State 2 & State 3 & State 4 & Average \\
\hline Middle-Aged Consumption & 49,759 & 42,505 & 30,520 & 32,188 & 38,966 \\
\hline Old Consumption & 49,441 & 17,093 & 68,680 & 27,410 & 40,433 \\
\hline Young Consumption & 19,000 & 19,000 & 19,000 & 19,000 & 19,000 \\
\hline Savings/Investment & 6,091 & 13,345 & 2,930 & 1,262 & 5,684 \\
\hline EquityInvestment & 4,784 & 3,483 & 782 & 985 & 2,546 \\
\hline Bond Investment & 1,307 & 9,862 & 2,148 & 277 & 3,138 \\
\hline Mean Equity Return & 9.69 & 7.31 & 16.04 & 17.20 & 12.65 \\
\hline Mean Bond Return & 5.51 & -0.95 & 6.23 & 13.15 & 6.32 \\
\hline Mean Equity Premium & 4.18 & 8.26 & 9.81 & 4.05 & 6.33 \\
\hline
\end{tabular}

Notes

This table shows the behavior of consumption, savings, equity/bond investment, and security returns across all four states with CRA (panel a) and IRA (panel b). Results are derived from the following calibration parameters: $E(y)=98,399, w^{0}=19,000 E\left(w^{1}\right)=44,650, \sigma(y) / E(y)=0.20$,

$\sigma\left(w^{1}\right) / E\left(w^{1}\right)=0.25, \operatorname{corr}\left(y, w^{1}\right)=0.1$, and $\operatorname{corr}\left(w^{1}, w^{1}\right)=\operatorname{corr}(y, y)=0.1$. The correlation between the middle-aged wage and the dividend is $\operatorname{corr}\left(w^{1}, d\right)=-0.4239$, whereas the long-run probabilities are: $P_{1}=$ $0.275 ; P_{2}=0.225 ; P_{3}=0.225$ and $P_{4}=0.275$. 
Table 7

Savings/Investment Levels: Increasing vs. Constant Risk Aversion

\begin{tabular}{|c|c|c|c|c|c|c|c|c|c|c|}
\hline & $i$ & $i i$ & $i i i$ & $i v$ & $\boldsymbol{v}$ & $v i$ & $v i i$ & viii & $i x$ & $x$ \\
\hline$a_{1}$ & 2.00 & 2.00 & 3.00 & 3.00 & 4.00 & 4.00 & 5.00 & 5.00 & 6.00 & 6.00 \\
\hline$a_{2}$ & 2.00 & 2.25 & 3.00 & 3.25 & 4.00 & 4.25 & 5.00 & 5.25 & 6.00 & 6.25 \\
\hline Middle-Aged Consumption & 32,288 & 41,715 & 32,168 & 40,238 & 32,137 & 38,966 & 31,856 & $\mathbf{3 7 , 8 5 5}$ & 31,590 & 36,893 \\
\hline Old Consumption & 47,111 & 37,684 & 47,231 & 39,161 & 47,262 & 40,433 & 47,543 & 41,544 & 47,809 & 42,506 \\
\hline Young Consumption & 19,000 & 19,000 & 19,000 & 19,000 & 19,000 & 19,000 & 19,000 & 19,000 & 19,000 & 19,000 \\
\hline Savings/Investment & 12,362 & 2,935 & 12,435 & 4,412 & 12,513 & 5,684 & 12,794 & 6,795 & 13,060 & 7,757 \\
\hline
\end{tabular}

Notes

This table presents the effects of risk aversion on the consumption of the three age-cohorts: young, middle-aged and old. It also shows the pattern of savings of the middle-aged with different risk aversion parameters. Results are reported for CRA and IRA. Results are derived from the following calibration parameters: $E(y)=98,399, w^{0}=19,000 E\left(w^{1}\right)=44,650, \sigma(y) / E(y)=0.20, \sigma\left(w^{1}\right) / E\left(w^{1}\right)=0.25, \operatorname{corr}\left(y, w^{1}\right)=0.1$, and $\operatorname{corr}\left(w^{1}, w^{1}\right)=\operatorname{corr}(y, y)=0.1$. The correlation between the middle-aged wage and the dividend is $\operatorname{corr}\left(w^{1}, d\right)=-0.4239$, whereas the long-run probabilities are: $P_{1}=0.275 ; P_{2}=0.225 ; P_{3}=0.225$ and $P_{4}=0.275$. 
Table 8

Portfolio Shares and Portfolio Allocations: Increasing vs. Constant Risk Aversion (Different Relative Increase in Risk Aversion)

\begin{tabular}{|c|c|c|c|c|c|c|c|c|c|c|}
\hline & $i$ & $i i$ & $i v$ & $v$ & $v i$ & $v i i$ & viii & $i x$ & $x$ & $x i$ \\
\hline$\alpha_{1}$ & 2.00 & 2.00 & 3.00 & 3.00 & 4.00 & 4.00 & 5.00 & 5.00 & 6.00 & 6.00 \\
\hline$\alpha_{2}$ & 2.00 & 2.25 & 3.00 & 3.25 & 4.00 & 4.25 & 5.00 & 5.25 & 6.00 & 6.25 \\
\hline Investment in Bond (Consol) & 2,701 & 1,378 & 3,805 & 2,364 & 4,700 & 3,138 & 5,277 & 3,725 & 5,611 & 4,168 \\
\hline Investment in Equity & 9,661 & 1,557 & 8,490 & 2,049 & 7,813 & 2,546 & 7,517 & 3,070 & 7,449 & 3,589 \\
\hline$\varphi^{S}$ & 27.69 & 6.57 & 27.54 & 9.88 & 28.03 & 12.73 & 28.65 & 15.22 & 29.25 & 17.37 \\
\hline$\varphi^{B}$ & 6.05 & 3.09 & 8.52 & 5.29 & 10.53 & 7.03 & 11.82 & 8.34 & 12.57 & 9.33 \\
\hline$\varphi^{E}$ & 21.64 & 3.49 & 19.02 & 4.59 & 17.50 & 5.70 & 16.84 & 6.88 & 16.68 & 8.04 \\
\hline$\omega^{B}$ & 0.218 & 0.470 & 0.309 & 0.536 & 0.376 & 0.552 & 0.412 & 0.548 & 0.430 & $\mathbf{0 . 5 3 7}$ \\
\hline$\omega^{E}$ & 0.782 & 0.530 & 0.691 & 0.464 & 0.624 & 0.448 & 0.588 & 0.452 & 0.570 & 0.463 \\
\hline
\end{tabular}

Notes

This table presents the effects of risk aversion on portfolio shares, portfolio allocation, and the total amount invested in equity and bonds. $\varphi^{\mathrm{S}}$ is the share of wealth saved/invested; $\varphi^{\mathrm{B}}$ is the share of wealth invested in bonds; $\varphi^{\mathrm{E}}$ is the share of wealth invested in equity; $\omega^{\mathrm{B}}$ is the portfolio share invested in bonds, $\omega^{\mathrm{E}}$ is the portfolio share invested in equity. Results are reported for CRA and IRA. Results are derived from the following calibration parameters: $E(y)=98,399, w^{0}=19,000 E\left(w^{1}\right)=44,650, \sigma(y) / E(y)=0.20, \sigma\left(w^{1}\right) / E\left(w^{1}\right)=0.25, \operatorname{corr}\left(y, w^{1}\right)=0.1$, and $\operatorname{corr}\left(w^{1}, w^{1}\right)=\operatorname{corr}(y, y)=0.1$. The correlation between the middle-aged wage and the dividend is $\operatorname{corr}\left(w^{1}, d\right)=-0.4239$, whereas the long-run probabilities are: $P_{1}=0.275 ; P_{2}=0.225 ; P_{3}=0.225$ and $P_{4}=0.275$. 
Table 9

Portfolio Shares and Portfolio Allocations: Increasing vs. Constant Risk Aversion (Same Relative Increase in Risk Aversion)

\begin{tabular}{c|ccc}
\hline \hline & $\boldsymbol{i}$ & $\boldsymbol{i i}$ & $\boldsymbol{i i i}$ \\
\hline \hline $\boldsymbol{\alpha}_{1}$ & 2.00 & $\mathbf{3 . 0 0}$ & $\mathbf{4 . 0 0}$ \\
$\boldsymbol{\alpha}_{2}$ & $\mathbf{2 . 2 5}$ & $\mathbf{3 . 3 7 5}$ & $\mathbf{4 . 5 0}$ \\
\hline Savings/Investments & $\mathbf{2 , 9 3 5}$ & $\mathbf{2 , 5 2 3}$ & $\mathbf{2 , 3 9 1}$ \\
Investment in Bond (Consol) & 1,378 & 1,642 & 1743 \\
Investment in Equity & 1,557 & 881 & 648 \\
$\varphi^{S}$ & 6.57 & 5.65 & 5.36 \\
$\varphi^{\boldsymbol{B}}$ & 3.09 & 3.68 & 3.90 \\
$\boldsymbol{\varphi}^{E}$ & 3.49 & 1.97 & 1.45 \\
$\boldsymbol{\omega}^{\boldsymbol{B}}$ & $\mathbf{0 . 4 7 0}$ & $\mathbf{0 . 6 5 1}$ & $\mathbf{0 . 7 2 9}$ \\
$\boldsymbol{\omega}^{E}$ & $\mathbf{0 . 5 3 0}$ & $\mathbf{0 . 3 4 9}$ & $\mathbf{0 . 2 7 1}$ \\
\hline \hline
\end{tabular}

Notes

This table presents the effects of risk aversion on portfolio shares, portfolio allocation, and the total amount invested in equity and bonds. $\varphi^{\mathrm{S}}$ is the share of wealth saved/invested; $\varphi^{\mathrm{B}}$ is the share of wealth invested in bonds; $\varphi^{\mathrm{E}}$ is the share of wealth invested in equity; $\omega^{\mathrm{B}}$ is the portfolio share invested in bonds, $\omega^{\mathrm{E}}$ is the portfolio share invested in equity. Results are derived from the following calibration parameters: $E(y)=98,399$,

$w^{0}=19,000 E\left(w^{1}\right)=44,650, \sigma(y) / E(y)=0.20, \sigma\left(w^{1}\right) / E\left(w^{1}\right)=0.25, \operatorname{corr}\left(y, w^{1}\right)=0.1$, and $\operatorname{corr}\left(w^{1}, w^{1}\right)=\operatorname{corr}(y, y)=0.1$. The correlation between the middle-aged wage and the dividend is $\operatorname{corr}\left(w^{1}, d\right)=-0.4239$, whereas the long-run probabilities are: $P_{1}=0.275 ; P_{2}=0.225 ; P_{3}=$ 0.225 and $P_{4}=0.275$. 